\title{
Peramalan Permintaan Keripik Singkong dengan Simulasi Monte Carlo
}

\section{Forecasting Demand for Cassava Chips with Monte Carlo Simulation}

\author{
Moh. Jufriyanto \\ Program Studi Teknik Industri, Fakultas Teknik, Universitas Muhammadiyah Gresik \\ Jl. Sumatera No 101 Gresik Kota Baru, Gresik Jawa Timur \\ E-mail: jufriyanto@umg.ac.id
}

\begin{abstract}
ABSTRAK
Strategi perencanaan produksi yang efektif dan efisien untuk menjaga keseimbangan antara permintaan dan persediaan dapat menggunakan pendekatan Peramalan permintaan. Studi kasus ini pada salah satu usaha keripik singkong. Permasalahan yang terjadi pada produk keripik singkong sering terjadi kekurangan dalam memenuhi permintaan konsumen. Selain itu, usaha ini hanya menggunakan perkiraan dalam mengatur produksi keripik singkong sehingga terjadi kekurangan pemenuhan permintaan. penelitian ini bertujuan melakukan peramalan permintaan keripik singkong. Peramalan permintaan ini guna meminimalisir ketidaksesuaian antara permintaan dengan persediaan produk keripik singkong. Metode yang digunakan yaitu simulasi monte carlo. Metode ini menggunakan pendekatan dengan probabilistik sehingga mampu mempertimbangkan ketidakpastian. Peramalan permintaan dilakukan selama dua belas bulan dan menggunakan data historis permintaan aktual pada tahun 2018 dan 2019. hasil peramalan permintaan pada tahun 2020 diperoleh total sebesar $45.958 \mathrm{~kg}$ dengan tingkat akurasi sebesar $98.68 \%$.
\end{abstract}

Kata Kunci: Peramalan, Simulasi Monte carlo, tingkat akurasi, Keripik Singkong.

\begin{abstract}
An effective and efficient production planning strategy to maintain a balance between demand and supply can use the demand forecasting approach. This case study is on a cassava chip business. Problems that occur in cassava chip products often have shortages in meeting consumer demand. In addition, this business only uses estimates in regulating the production of cassava chips, resulting in a lack of fulfillment of demand. This study aims to forecast the demand for cassava chips. This demand forecasting is to minimize the mismatch between demand and supply of cassava chips. The method used is the monte carlo simulation. This method uses a probabilistic approach so that it is able to consider uncertainty. Demand forecasting was carried out for twelve months and used historical data on actual demand in 2018 and 2019. The results of demand forecasting in 2020 obtained a total of $45.958 \mathrm{~kg}$ with an accuracy rate of $98.68 \%$.
\end{abstract}

Keywords: Forecasting, Monte carlo Simulation, Accuracy Rate, Cassava Chips.

\section{Pendahuluan}

Analisis peramalan permintaan produk selalu dilakukan oleh manjemen produksi terkait dengan perencanaan yang berhubungan dengan pemenuhan kebutuhan konsumen, rencana kebutuhan tenaga kerja, penentuan dan perencanaan kapasitas produksi, penentuan lokasi dan jadwal produksi. Peramalan menjadi salah satu hal penting yang dimiliki perusahaan atau organisasi berkaitan dengan bisnis pada saat pengambilan keputusan oleh manajemen(Ngantung \& Jan, 2019).Jumlah permintaan tidak sesuai dengan hasil produksi, maka produk akan tersimpan pada ruang penyimpanan dengan waktu yang sangat lama. Sedangkan ruang menyimpanan memiliki keterbatasan tempat dan waktu penyimpanan.
Permasalahan ini harus diselesaikan agar tidak terjadi penumpukan hasil produksi. Salah satu teknik yang digunakan adalah peramalan permintaan(Ridho et al., 2019).

Strategi perencanaan terhadap produk yang ditawarkan agar sesuai dengan permintaan konsumen di masa yang akan datang dapat menggunakan metode peramalan. Metode peramalan merupakan salah satu cara memprediksi tingkat permintaan pada masa yang akan dating (Utamie, Isdiantoni, \& Kurniawan, 2019). Bervariasinya jenis produk dan jumlah permintaan yang tidak pasti, mengakibatkan perusahaan tidak bisa mengatur jumlah penyimpanan produk di gudang. Permasalahan tersebut membuat barang tidak tersedia pada saat terdapat permintaan konsumen. Sebaliknya, produksi yang berlebihan 
akan mengakibatkan penumpukan di gudang. Perusahaan perlu melakukan peramalan permintaan agar hasil produksi dapat disesuaikan dengan permintaan konsumen (Samuel et al., 2020).

Peramalan permintaan menjadi strategi yang dapat diambil oleh perusahaan untuk perencanaan produksi yang efektif dan efisien. Selain itu, perusahaan dapat menyelesaikan permasalahan pemenuhan permintaan yang bersifak fluktuatif (Wijayanti \& Rosydi, 2019). Ketidaksesuaian Persediaan dan penjualan yang dilakukan oleh perusahaan, mengakibatkan kelebihan persediaan di gudang. Salah satu cara mengatasi permasalahan ini dengan melakukan peramalan permintaan produk agar jumlah persediaan dapat disesuaikan dengan kebutuhan produk (Sofyan \& Meutia, 2019).

Proses peramalan pada perusahaan berfokus pada perkiraan produk, persediaan, penjadwalan, permintaan konsumen, investasi modal, transportasi distribusi produk dan pemasaran produk. Proses permalan berdasarkan data dari periode sebelumnya meliputi parameter waktu. Hal ini memberikan keuntungan bagi perusahaan dalam melakukan perencanaan yang efektif dan efisien (Auliasari, Kertaningtyas, \& Kriswantono, 2020).

Pemenuhan terhadap pemesanan yang dilakukan oleh konsumen meliputi produk, bahan baku, dapat menggunakan metode peramalan. Perhitungan peramalan yang tepat dapat menghasilkan prediksi jumlah barang yang tersedia berdasarkan permintaan konsumen (Lusiana \& Yuliarty, 2020). Usaha mikro kecil dan menengah merupakan salah satu usaha kegiatan ekonomi yang bergerak pada produksi barang atau jasa. UMKM memiliki peranan penting dalam pembangunan perekonomian di daerah atau pusat (Jufriyanto, 2020).

Salah satu UMKM yaitu UMKM Difa. Usaha mikro, kecil dan menengah difaa merupakan usaha yang bergerak pada produksi makanan ringan seperti keripik singkong, keripik tempe, ikan teri krispi, dan juga kacang karpis goring. UMKM Difaa merupakan salah satu sentra usaha pada keripik singkong.UMKM Difaa tergolong dalam skala industri kecil menengah. Usaha yang masih tergolong skala kecil masih belum memiliki struktur yang tidak begitu teratur dan belum memiliki perencanaan yang begitu spesifik dan teliti dalam mengelola industri secara keseluruhan. Sistem produksi yang dilakukan oleh UMKM Difaa menggunakan make to stock untuk pelanggan umum dan make to order untuk pelanggan tetap.

Permasalahan yang terjadi pada produk keripik singkong pada pelanggan umum menggunakan sistem make to stock. Pada produk ini sering terjadi kekurangan dalam memenuhi permintaan konsumen. Pihak UMKM Difaa hanya menggunakan perkiraan atau intuisi saja dalam mengatur produksi kerupuk singkong, sehingga jumlah produksi tidak mampu memenuhi permintaan dari konsumen. Contoh pada tahun 2018 terdapat permintaan sebesar $46004 \mathrm{~kg}$, namun karena penggunaan perkiraan atau intuisi, maka produksi yang dihasilkan $45550 \mathrm{~kg}$ dan terjadi kekurangan pemenuhan permintaan sebesar $454 \mathrm{~kg}$.

Permintaan konsumen yang tidak terpenuhi sering melakukan komplain kepada pihak UMKM Difaa. Dampak dari permasalahan tersebut membuat kepuasan konsumen menurun. Konsumen yang tidak terpenuhi permintaannya akan beralih pada produsen lain. Selain itu, pihak UMKM Difaa memberikan biaya pengganti untuk permintaan konsumen yang tidak terpenuhi seperti menggratistikan biaya pengiriman.

Berdasarkan permsalahan tersebut, maka tujuan penelitian ingin melakukan peramalan permintaan keripik singkong. Peramalan permintaan ini guna meminimalisir ketidaksesuaian antara permintaan dengan persediaan produk yaitu keripik singkong. Selain itu, juga mngantisipasi terjadinya ketidakpastian permintaan dari konsumen.

Pada penelitian ini menggunakan simulasi monte carlo untuk peramalan. Simulasi mote carlo merupakan teknik simulasi probabilistik pada penyelesaian masalah dengan sampling dan proses random (Yusmaity, Julius, \& Yuhandri, 2019). Pendekatan dengan perobabilistik ini mampu mempertimbangkan ketidakpastian yang dimungkinkan terjadi. Selain itu metode ini cukup sederhana dalam menguraikan dan menyelesaikan persoalan (Rahim \& Fuad, 2019) (Wijaya \& Hendrik, 2019).

\section{Metode Penelitian}

Pada tahap ini menjelaskan tentang pengumpulan data dan pengolahan data. Pada pengumpulan data merupakan data historis dari permintaan, sedangkan pada pengolahan data tentang perosedur simulasi montecarlo.

\section{Pengumpulan Data}

Pada tahap pengumpulan data merupakan data historis dari permintaan keripik singkong kemasan 250 gram pada tahun 2018 dan tahun 2019. Adapun data tersebut diperoleh dari UMKM Difaa. Berikut merupakan data permintaan keripik singkong yaitu:

Tabel 1. Data historis permintaan keripik singkong tahun 2018

\begin{tabular}{lc}
\hline Bulan & $\begin{array}{c}\text { Tahun 2018 } \\
(\mathrm{Kg})\end{array}$ \\
\hline Januari & 3471 \\
\hline
\end{tabular}




\begin{tabular}{ll}
\hline Februari & 3934 \\
Maret & 3250 \\
April & 3337 \\
Mei & 3892 \\
Juni & 4031 \\
Juli & 4285 \\
Agustus & 3639 \\
September & 3886 \\
Oktober & 4109 \\
November & 4104 \\
Desember & 4066 \\
Total & 46004 \\
\hline
\end{tabular}

Tabel 2. Data historis permintaan keripik singkong tahun 2019

\begin{tabular}{lc}
\multicolumn{2}{c}{2019} \\
\hline Bulan & $\begin{array}{c}\text { Tahun 2019 } \\
(\mathrm{Kg})\end{array}$ \\
\hline Januari & 3518 \\
Februari & 3483 \\
Maret & 3381 \\
April & 3248 \\
Mei & 3769 \\
Juni & 4105 \\
Juli & 3457 \\
Agustus & 3602 \\
September & 4572 \\
Oktober & 4112 \\
November & 4073 \\
Desember & 4034 \\
Total & 45354 \\
\hline
\end{tabular}

\section{Pengolahan Data}

Pada tahap ini merupakan pengolahan terhadap data yang diperoleh. Pengolahan data menggunakan simulasi monte carlo untuk mendapatkan hasil peramalan. Peramalan yang dilakukan sebanyak 12 periode pada masa yang akan datang. Adapun tahapan dari simulasi monte carlo yaitu (Geni, Santony, \& Sumijan, 2019):

a. Penentuan distribusi probabilitas dari jumlah permintaan. Distribusi probabilitas merupakan distribusi yang menggambarkan peluang dari sekumpulan variabel sebagai pengganti frekuensi. Adapun rumusnya yaitu :

$$
\mathrm{P} \quad=\mathrm{F} / \mathrm{J}
$$

Keterangan :

$\mathrm{P} \quad=$ distribusi probabilitas ke- $\mathrm{i}$

$$
\begin{aligned}
\mathrm{F} & =\text { frekuensi } \\
\mathrm{J} & =\text { jumlah }
\end{aligned}
$$

b. Penentuan distribusi probabilitas kumulatif.

c. Penentuan interval angka acak.

d. Pembangkitan bilangan random (acak). Salah satu teknik pembangkitan bilangan random yaitu LCG (Linear Congruential Generator). Adapun rumusnya yaitu :

$$
\begin{aligned}
\mathrm{Z}_{\mathrm{i}} & =\left(\mathrm{a} \times\left(\mathrm{Z}_{\mathrm{i}-1}\right)+\mathrm{c}\right) \bmod \mathrm{m} \\
\mathrm{U}_{\mathrm{i}} & =\mathrm{Z}_{\mathrm{i}} / \mathrm{m}
\end{aligned}
$$

Keterangan :

a = faktor pengali

c $=$ angka konstan yang bersyarat (increment).

$\mathrm{m}=$ modulus (modulo)

$\mathrm{Z}_{0} \quad=$ kunci pembangkit (bibit)

$\mathrm{Z}_{\mathrm{i}} \quad=$ hasil bilangan

$\mathrm{U}_{\mathrm{i}} \quad=$ bilangan acak ke-i

Pembangkitan bilangan acak dilakukan sebanyak 12 sesuai dengan peramalan permintaan yaitu 12 periode

e. Melakukan peramalan dengan menggunakan prosedur simulasi.

\section{Hasil dan Pembahasan}

Pada tahap ini menjelaskan hasil dari pengolahan data berdasarkan data yang diperoleh dari pengumpulan data.

\section{Penentuan Distribusi Probabilitas}

Pehitungan penentuan distribusi probabilitas dilakukan pada masing-masing permintaan pada setiap periode. Contoh perhitungan distribusi probabilitas pada bulan januari tahun 2018 sebagai berikut :

$\mathrm{P}($ januari $)=\frac{\text { Jumlah permintaan bulan januari }}{\text { Total jumlah permintaan }}=\frac{3471}{46004}$ $\mathrm{P}($ januari $)=0,075 \approx 0,08$

Adapun hasil dari perhitungan distribusi probabilitas secara keseluruhan dapat dilihat pada pada tabel 3 dan tabel 4.

Tabel 3. Distribusi probabilitas permintaan rahun 2018

\begin{tabular}{lcc} 
Bulan & $\begin{array}{c}\text { Tahun 2018 } \\
(\mathrm{Kg})\end{array}$ & $\begin{array}{c}\text { Distribusi } \\
\text { probabilitas }\end{array}$ \\
\hline Januari & 3471 & 0.08 \\
Februari & 3934 & 0.09 \\
Maret & 3250 & 0.07 \\
April & 3337 & 0.07 \\
Mei & 3892 & 0.08 \\
Juni & 4031 & 0.09 \\
Juli & 4285 & 0.09 \\
Agustus & 3639 & 0.08 \\
September & 3886 & 0.08 \\
\hline
\end{tabular}




\begin{tabular}{lcc}
\hline Oktober & 4109 & 0.09 \\
November & 4104 & 0.09 \\
Desember & 4066 & 0.09 \\
Total & 46004 & 1.0 \\
\hline
\end{tabular}

Tabel 4. Distribusi probabilitas permintaan tahun 2019

\begin{tabular}{lcc}
\multicolumn{1}{c}{ Bulan } & $\begin{array}{c}\text { Tahun 2019 } \\
(\mathrm{Kg})\end{array}$ & $\begin{array}{c}\text { Distribusi } \\
\text { probabilitas }\end{array}$ \\
\hline Januari & 3518 & 0.08 \\
Februari & 3483 & 0.08 \\
Maret & 3381 & 0.07 \\
April & 3248 & 0.07 \\
Mei & 3769 & 0.08 \\
Juni & 4105 & 0.09 \\
Juli & 3457 & 0.08 \\
Agustus & 3602 & 0.08 \\
September & 4572 & 0.10 \\
Oktober & 4112 & 0.09 \\
November & 4073 & 0.09 \\
Desember & 4034 & 0.09 \\
Total & 45354 & 1.0 \\
\hline
\end{tabular}

Pada tabel 3 dan 4 merupakan pehitungan hasil distribusi probabilitas atau nilai peluang yang akan dijadikan pengganti frekuensi kejadian dari setiap variabel. Contoh hasil perhitungan pada bulan januari pada tahun 2018 diperoleh nilai distribusi probabilitas sebesar 0,08 dan pada tahun 2019 diperoleh nilai distribusi probabilitas sebesar 0,08 juga.

\section{Penentuan Distribusi Probabilitas Kumulatif}

Pada perhitungan distribusi probabilitas kumulatif merupakan penjumlahan distribusi probabilitas variabel tertentu dengan vaiabel sebelumnya, kecuali untuk varibel pertama. Adapun hasil perhitungannya pada tabel 5 dan tabel 6:

Tabel 5. Distribusi probabilitas kumulatif tahun 2018

\begin{tabular}{lccc} 
Bulan & $\begin{array}{c}\text { Tahun } \\
\text { 2018 }(\mathrm{Kg})\end{array}$ & $\begin{array}{c}\text { Distribusi } \\
\text { probabilitas }\end{array}$ & $\begin{array}{c}\text { Distribusi } \\
\text { probabilitas } \\
\text { kumlatif }\end{array}$ \\
\hline Januari & 3471 & 0.08 & 0.08 \\
Februari & 3934 & 0.09 & 0.17 \\
Maret & 3250 & 0.07 & 0.24 \\
April & 3337 & 0.07 & 0.31 \\
Mei & 3892 & 0.08 & 0.39 \\
\hline
\end{tabular}

\begin{tabular}{lccc}
\hline Juni & 4031 & 0.09 & 0.48 \\
Juli & 4285 & 0.09 & 0.57 \\
Agustus & 3639 & 0.08 & 0.65 \\
September & 3886 & 0.08 & 0.74 \\
Oktober & 4109 & 0.09 & 0.83 \\
November & 4104 & 0.09 & 0.91 \\
Desember & 4066 & 0.09 & 1.00 \\
Total & 46004 & 1.0 & \\
\hline
\end{tabular}

Tabel 6. Distribusi probabilitas kumulatif tahun 2019

\begin{tabular}{lccc}
\hline \multicolumn{1}{c}{ Bulan } & $\begin{array}{c}\text { Tahun 2019 } \\
(\mathrm{Kg})\end{array}$ & $\begin{array}{c}\text { Distribusi } \\
\text { probabilitas }\end{array}$ & $\begin{array}{c}\text { Distribusi } \\
\text { probabilitas } \\
\text { kumlatif }\end{array}$ \\
\hline Januari & 3518 & 0.08 & 0.08 \\
Februari & 3483 & 0.08 & 0.16 \\
Maret & 3381 & 0.07 & 0.23 \\
April & 3248 & 0.07 & 0.30 \\
Mei & 3769 & 0.08 & 0.38 \\
Juni & 4105 & 0.09 & 0.47 \\
Juli & 3457 & 0.08 & 0.55 \\
Agustus & 3602 & 0.08 & 0.63 \\
September & 4572 & 0.10 & 0.73 \\
Oktober & 4112 & 0.09 & 0.82 \\
November & 4073 & 0.09 & 0.91 \\
Desember & 4034 & 0.09 & 1.00 \\
Total & 45354 & 1.0 & \\
\hline
\end{tabular}

Pada tabel 5 dan 6 merupakan hasil perhitungan distribusi probabilitas kumulatif. Contoh perhitungan distribusi probabilitas kumulatif pada bulan februari pada tahun 2018 merupakan hasil penjumlah dari nilai distribusi probabilitas bulan januari dan februari yaitu $0,08+0,09=0,17$. Hasil perhitungan pada tabel 5 dan 6 akan dijadikan sebagai pedoman dalam penentuan interval angka acak.

\section{Penentuan Interval Angka Acak}

Pada perhitungan interval angka acak digunakan untuk mencari nilai pembatas yaitu minimal dan maksimal. Pembuatan interval angka acak berdasarkan tabel pada penentuan distribusi kumulatif pada tabel 5 untuk permintaan pada tahun 2018 dan tabel 6 untuk permintaan pada tahun 2019. Nilai pembatas untuk permulaan interval angka acak selalu dimulai dengan angak 0 (nol) sebagai nilai yang paling terendah (paling minimal). Hasil nilai dari interval angka acak dapat dilihat pada tabel 7 dan tabel 8 .

Tabel 7. Interval angka acak permintaan tahun 2018 


\begin{tabular}{lcc}
\hline \multicolumn{1}{c}{ Bulan } & $\begin{array}{c}\text { Tahun 2018 } \\
(\mathrm{Kg})\end{array}$ & $\begin{array}{c}\text { Interval angka } \\
\text { acak }\end{array}$ \\
\hline Januari & 3471 & $0-0.08$ \\
Februari & 3934 & $0.09-0.17$ \\
Maret & 3250 & $0.18-0.24$ \\
April & 3337 & $0.25-0.31$ \\
Mei & 3892 & $0.32-0.39$ \\
Juni & 4031 & $0.41-0.48$ \\
Juli & 4285 & $0.49-0.57$ \\
Agustus & 3639 & $0.58-0.65$ \\
September & 3886 & $0.66-0.74$ \\
Oktober & 4109 & $0.75-0.83$ \\
November & 4104 & $0.84-0.91$ \\
Desember & 4066 & $0.92-1$ \\
Total & 46004 & \\
\hline
\end{tabular}

Tabel 8. Interval angka acak permintaan tahun 2019

\begin{tabular}{lcc}
\multicolumn{1}{c}{ Bulan } & $\begin{array}{c}\text { Tahun 2019 } \\
(\mathrm{Kg})\end{array}$ & $\begin{array}{c}\text { Interval angka } \\
\text { acak }\end{array}$ \\
\hline Januari & 3518 & $0-0.08$ \\
Februari & 3483 & $0.09-0.16$ \\
Maret & 3381 & $0.17-0.23$ \\
April & 3248 & $0.24-0.30$ \\
Mei & 3769 & $0.31-0.38$ \\
Juni & 4105 & $0.39-0.47$ \\
Juli & 3457 & $0.48-0.55$ \\
Agustus & 3602 & $0.56-0.63$ \\
September & 4572 & $0.64-0.73$ \\
Oktober & 4112 & $0.74-0.82$ \\
November & 4073 & $0.83-0.91$ \\
Desember & 4034 & $0.92-1$ \\
Total & 45354 & \\
\hline
\end{tabular}

Pada tabel tabel 7 dan 8 menjelaskan interval angka acak dari masing-masing permintaan. Hasil dari interval angka acak akan dijadikan pedoman dalam melakukan proses simulasi untuk menghasilkan hasil peramalan.

\section{Pembangkitan Bilangan Acak (Random)}

Pembangkitan bilangan acak menggunakan LCG (Linear Congruential Generator). Komponen untuk proses perhitungan terdiri dari nilai $\mathrm{a}=13, \mathrm{c}=35$,
$\mathrm{Z}_{0}=20, \mathrm{~m}=99$. Adapun contoh perhitungannya sebagai berikut :

$$
\begin{array}{ll}
\mathrm{Z}_{1} & =\left(\left(\mathrm{a} \times \mathrm{Z}_{\mathrm{i}-1}\right)+\mathrm{c}\right) \bmod \mathrm{m} \\
\mathrm{Z}_{1} & =\left(\left(\mathrm{a} \times \mathrm{Z}_{1-1}\right)+\mathrm{c}\right) \bmod \mathrm{m} \\
\mathrm{Z}_{1} & =\left(\left(\mathrm{a} \times \mathrm{Z}_{0}\right)+\mathrm{c}\right) \bmod \mathrm{m} \\
\mathrm{Z}_{1} & =((13 \times 20)+35) \bmod 99 \\
\mathrm{Z}_{1} & =30 \\
\mathrm{U}_{1} & =\mathrm{Z}_{1} / \mathrm{m}=30 / 99 \\
\mathrm{U}_{1} & =0.34
\end{array}
$$

Adapun hasil keseluruhan pembangkitan bilangan acak dapat dilihat pada tabel 9.

Tabel 9. Hasil pembangkitan bilangan acak

\begin{tabular}{lcc}
\hline \multicolumn{1}{c}{ Bulan } & $\mathrm{Zi}$ & $\mathrm{Ui}$ \\
\hline Januari & 30 & 0.34 \\
Februari & 40 & 0.45 \\
Maret & 50 & 0.56 \\
April & 60 & 0.67 \\
Mei & 70 & 0.79 \\
Juni & 80 & 0.90 \\
Juli & 1 & 0.01 \\
Agustus & 11 & 0.12 \\
September & 21 & 0.24 \\
Oktober & 31 & 0.35 \\
November & 41 & 0.46 \\
Desember & 51 & 0.57 \\
\hline
\end{tabular}

\section{Hasil Peramalan Permintaan}

Peramalan permintaan keripik singkong dilakukan pada masing-masing tahun. Percobaan simulasi monte carlo menggunakan pembangkitan bilangan acak sebanyak 1 kali percobaan (1 iterasi). Adapun hasil peramalan permintaan keripik singkong dengan simulasi monte carlo yaitu :

Tabel 10. Hasil peramalan permintaan keripik singkong berdasarkan simulasi monte carlo untuk periode berikutnya

\begin{tabular}{lc}
\multicolumn{2}{c}{ (tahun 2019) } \\
\hline \multicolumn{1}{c}{ Bulan } & $\begin{array}{c}\text { Hasil } \\
\text { Peramalan } \\
(\mathrm{Kg})\end{array}$ \\
\hline Januari & 3892 \\
Februari & 4031 \\
Maret & 4285 \\
April & 3886 \\
Mei & 4109 \\
Juni & 4104 \\
Juli & 3471 \\
Agustus & 3934 \\
September & 3250 \\
\hline
\end{tabular}




\begin{tabular}{lc}
\hline Oktober & 3892 \\
November & 4031 \\
Desember & 4385 \\
Total & 47170 \\
\hline
\end{tabular}

Pada tabel 10 menjelaskan hasil peramalan permintaan keripik singkong dengan menggunakan simulasi monte carlo. Dari hasil peramalan diperoleh bahwa total peramalan permintaan keripik singkong sebesar $47170 \mathrm{~kg}$.

Dari hasil tersebut diperoleh perhitungan tingkat akurasi permintaan aktual dengan hasil peramalan permintaan sebagai berikut :

$$
\begin{aligned}
\text { Tingkat akurasi } & =\frac{\text { Total hasl permintaan aktual }}{\text { Total hasil peramalan permintaan }} \\
\text { Tingkat akurasi } & =\frac{46004}{47170}=0,9753 \\
\text { Tingkat akurasi } & =97,53 \%
\end{aligned}
$$

Dari hasil perhitungan, dapat dijelaskan bahwa prosentase hasil peramalan permintaan keripik singkong mampu memberikan keakuratan sebesar 97,53\% berdasarkan data historis permintaan aktual periode sebelumnya.

Tabel 11. Hasil peramalan permintaan keripik singkong berdasarkan simulasi monte carlo untuk periode berikutnya (tahun 2020)

\begin{tabular}{lc}
\hline \multicolumn{1}{c}{ Bulan } & $\begin{array}{c}\text { Hasil } \\
\text { Peramalan }(\mathrm{Kg})\end{array}$ \\
\hline Januari & 3769 \\
Februari & 4105 \\
Maret & 3602 \\
April & 4572 \\
Mei & 4112 \\
Juni & 4073 \\
Juli & 3518 \\
Agustus & 3483 \\
September & 3248 \\
Oktober & 3769 \\
November & 4105 \\
Desember & 3602 \\
Total & 45958 \\
\hline
\end{tabular}

Pada tabel 11 menjelaskan hasil peramalan permintaan keripik singkong dengan menggunakan simulasi monte carlo. Dari hasil peramalan diperoleh bahwa total peramalan permintaan keripik singkong sebesar $45958 \mathrm{~kg}$.

Dari hasil tersebut diperoleh perhitungan tingkat akurasi permintaan aktual dengan hasil peramalan permintaan sebagai berikut :

$$
\begin{aligned}
\text { Tingkat akurasi } & =\frac{\text { Total hasl permintaan aktual }}{\text { Total hasil peramalan permintaan }} \\
\text { Tingkat akurasi } & =\frac{45354}{45958}=0,9868 \\
\text { Tingkat akurasi } & =98,68 \%
\end{aligned}
$$

Dari hasil perhitungan, dapat dijelaskan bahwa prosentase hasil peramalan permintaan keripik singkonguntul periode berikutnya, mampu memberikan kekuratan sebesar 98,68\% berdasarkan data historis permintaan aktual periode sebelumnya.

Dari hasil perhitungan peramalan tersebut, ditampilkan pada grafik untuk memberikan informasi secara visual. Adapaun grafik dapat dilihat pada gambar 2 dan 3 sebagai berikut :

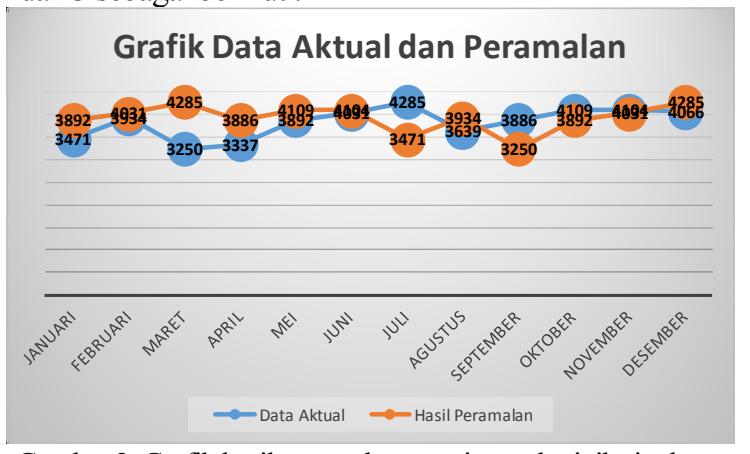

Gambar 2. Grafik hasil peramalan permintaan keripik singkong pada peride berikutnya (tahun 2019)

Pada gambar 2 menjelaskan hasil peramalan permintaan keripik singkong untuk periode selanjutnya berdasarkan data permintaan aktual pada tahun 2018 . Hasil grafik memberikan infomasi permintaan untuk masing-masing bulan, Misal pada bulan januari diperoleh hasil peramalan permintaan sebesar $3982 \mathrm{~kg}$ keripik singkong.

Pada gambar 3 menjelaskan hasil peramalan permintaan keripik singkong untuk periode selanjutnya berdasarkan data permintaan aktual pada tahun 2019 . Hasil grafik memberikan infomasi terhadap permintaan untuk masing-masing bulan, Misal pada bulan januari diperoleh hasil peramalan permintaan sebesar $3769 \mathrm{~kg}$ keripik singkong.

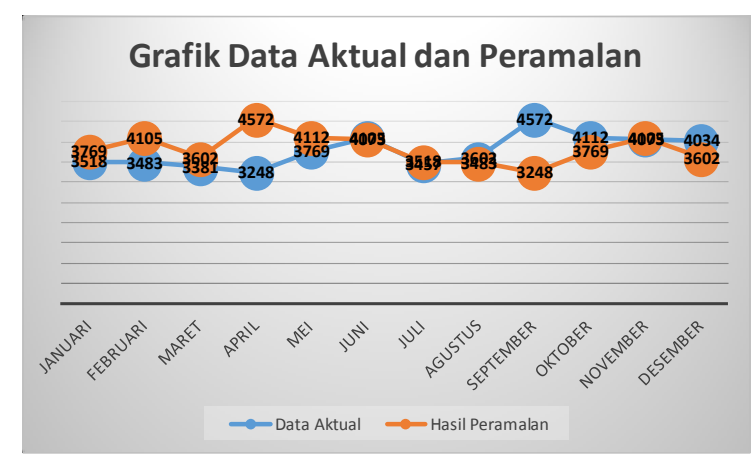

Gambar 3. Grafik hasil peramalan permintaan keripik singkong untuk permintaan tahun 2019 


\section{Kesimpulan}

Berdasarkan hasil pengolahan data, maka dapat disimpulkan dari penelitian yaitu, bahwa hasil peramalan permintaan keripik singkong berdasarkan simulasi monte carlountuk periode selanjutnya (tahun 2019) berdasarkan data permintaan aktual pada tahun 2018 diperoleh total sebesar $47170 \mathrm{~kg}$ dan tingkat akurasi peramalan sebesar 97,53\%. Dari hasil tersebut maka dapat dikatakan peramalan permintaan keripik singkong mampu memberikan keakuratan yang baik terhadap permintaan aktual. Sedangkan hasil peramalan permintaan keripik singkong berdasarkan simulasi monte carlo untuk periode selanjutnya (tahun 2020) berdasarkan data pada tahun 2019 , diperoleh total sebesar $45958 \mathrm{~kg}$. Hasil pengukuran tingkat akurasi sebesar 98,68\%. Dari hasil tersebut dapat digambarkan bahwa hasil peramalan permintaan mampu memberikan tingkat pengukuran keakuratan yang baik dalam pemenuan kebutuhan keripik singkong. Hasil ini dapat memberikan informasi kepada pihak UMKM Difaa untuk mengevaluasi perencanaan produksi yang akan dilakukan, sehingga pemenuhan permintaan konsumen dapat terpenuhi dan kepuasan konsumen semakin meningkat.

Pada penelitian selanjutnya dapat melakukan perencanaan aggregat terhadap kebutuhan produk sehigga jadwal produksi dapat dilakukan secara baik, selain itu juga dapat melakukan perencanaan kebutuhan baku untuk produksi keripik singkong.

\section{Daftar Pustaka}

Auliasari, K., Kertaningtyas, M., \& Kriswantono, M. (2020). Penerapan Metode Peramalan untuk Identifikasi Permintaan Konsumen. INFORMAL: Informatics Journal, 4(3), 121.

Geni, Y. B., Santony, J., \& Sumijan. (2019). Prediksi Pendapatan Terbesar pada Penjualan Produk Cat dengan Menggunakan Metode Monte Carlo. Informatika Ekonomi Bisnis, 1(4), 15-20.

Jufriyanto, M. (2020). Strategi Peningkatan Daya Saing dan Pengembangan Usaha Kerupuk Ikan Tuna $\mathrm{Hj}$. Zainah dengan Analytic Network Process. Sains, Teknologi Dan Industri, 17(2), 65-72.
Lusiana, A., \& Yuliarty, P. (2020). Penerapan Metode Peramalan (Forecasting) Pada Permintaan Atap Di PT. X. Industri Inovatif: Jurnal Teknik Industri, 10(1), 11-20.

Ngantung, M., \& Jan, H. A. (2019). Analisis Peramalan Permintaan Obat Antibiotik Pada Apotik Edelweis Tatelu. Jurnal EMBA: Jurnal Riset Ekonomi, Manajemen, Bisnis Dan Akuntansi, 7(4), 4859-4867.

Rahim, R., \& Fuad, N. R. (2019). Aplikasi dalam simulasi penjualan dengan menggunakan metode monte carlo. Ready Star, 2(1), 235-239.

Ridho et al. (2019). Peramalan Permintaan Produk pada Permainan Hay Day. Seminar Nasional Inovasi Dan Aplikasi Teknologi Di Industri 2019, (February), 74-80.

Samuel et al. (2020). Penentuan Metode Peramalan Permintaan Barang Setengah Jadi Di PT. XYZ. Ilmiah Teknik Industri, 8(1), 7-17.

Sofyan, K. D., \& Meutia, S. (2019). Peramalan Permintaan Produk Di PT. Bina Usaha Bersama Sehati Lhokseumawe. SNTI 2019, 1-9.

Utamie, B. L., Isdiantoni, \& Kurniawan, T. D. (2019). Peramalan Permintaan Buah di Kabupaten Sumenep. Seminar Nasional Optimalisasi Sumberdaya Lokal Di Era Revolusi Industri 4.0, 155-166.

Wijaya, S. F., \& Hendrik, S. (2019). Penerapan Metode Monte Carlo Pada Penjadwalan Proyek Serpong Garden Apartment. Mitra Teknik Sipil, 2(3), 189-198.

Wijayanti, E., \& Rosydi, K. (2019). Peramalan Permintaan Dengan Pendekatan Time Series Dan Perencanaan Produksi Agregat. Knowledge Industrial Engineering, 06(02), 75-80.

Yusmaity, Julius, S., \& Yuhandri. (2019). Simulasi Monte Carlo untuk Memprediksi Hasil Ujian Nasional (Studi Kasus di SMKN 2 Pekanbaru). Jurnal Informasi \& Teknologi, 1(4), 1-6 